\title{
Study of Hereditary Transmission of Papillary Patterns
}

\author{
Vasily Yarovenko \\ Doctor of law, Professor of Law school, Far Eastern Federal University, \\ The Honored of law the Russian Federation, Vladivostok, Russia
}

Doi:10.5901/mjss.2015.v6n4s3p264

\begin{abstract}
The paper considers the historically considered scientific disputes by various authors about the hereditary transmission of papillary pattern. A dermatoglyphic study now revealed the existence of the general laws pass those traits are inherited. The children are dominated by the same elements papillary pattern (loops, spirals or arc) as the parents. In combinations of patterns on the fingers, most children have a parent forms, but their nature and frequency for each finger is different. The twins, brothers or sisters have the same types of graphics for all your fingers, but they are significantly different parameters such as crests through, shape, symmetry, slope, etc. Random probability of a similar match negligible. In heritance of dermatoglyphic traits allows them to be used in determining paternity, determining the identity of the deceased to his close relatives, also create likely search forensic model of offender. The author justified conclusion on the continuation of the research methods of system types of papillary pattern, and their ratio on your fingers, form and other type of dermatoglyphic features for more information about the subject.
\end{abstract}

Keywords: information, people, papillary patterns, psychological portrait, fingerprinting, dermatoglyphics.

\section{Introduction}

One of the directions in dermatoglyphic is the study of the general laws the hereditary transmission of papillary pattern. So R. Gejndl' in his work leads the historical facts of the educational buildings in Chinese cities who have been orphans and children planted. The House near the door there was a drawer opening from the outside. There relatives put the child and gave a bamboo drum that arrives, a new guest. Gatekeeper opened from inside the drawer without looking at the one who brought it, and pass the little creature to head home. Pre admission formalities were performed to establish the identity of the child. Age and gender are entered into the registry. If age has not been established, the profile in the book the day and hour admission to the shelter. Followed by exact description would take: a description of the form of the skull, limbs, curl hair, random birthmarks, etc. and finally the fingerprints.

The most stressed, because every Chinese mother accurately informed about the patterns over the toes of her newborn and later to eliminate the unfortunate circumstances that prompted her to return the child, take it back, giving an accurate description of the patterns of lines and papillary ones, so having your child (Gejndl', 1927).

The question arises how illiterate do not have photographic memory Chinese women, not only in detail visually remember the patterns, but also with great precision in their subsequent describe? The phenomenon of growth leads to changes in the pattern of finger proportions, but leaves them figure unchanged from birth (Komissarov, Levin, 1997).

Because the patterns from newborn have small dimensions, the better their review and memorization, probably the mother as a guideline to use his drawings fingers hands. And then, regardless of the length of time to match their prints from prints of a child and determined the identity of the child. In this process, in our view, already contained elements mediated transmission of papillary child identification patterns through related genetic connection.

L.I. Tegako results the results of studies of individual authors: F. Galton, E.M. Elderton, K. Bonnevie, M.V. Volotckogo and etc. (Tegako, 2010), that are of interest from the perspective of the history and problem solution the hereditary transmission of papillary pattern. Where possible we have the necessary information.

So, L.I. Tegako noted that inheritance skin pictures wanted F. Galton, who reviewed the drawings at the twins, papillary and noted that patterns actually are not inherited, but still are in pure form from forefathers to offspring (Galton, 1892). According to E.M. Elderton, if both parents on the big fingers of both hands were curved patterns, the children to these fingers never curls (dvudel'tovyh) patterns. Conversely, if the parents on these fingers curls, the children never is arc. (Elderton, 1920).

In front of the Forgeot (1892) stated clearly that never met never transfer patterns inherited, though for this purpose traced three generations. The same spoken Senet (1906) based on the study of patterns of fingers 5-star 
generations that heredity plays no role in daktilogramme. Stockis (1908) considered hereditary transmission of legend.

A more cautious approach to the issue Cevidalli (1908), recognizing predisposition to hereditary transmission, if not absolute accuracy, all the same to some similarities. Finding rare patterns of two generations, in his view, can be used as a secondary proof of paternity.

Benassi (1908-1909) has said that if the same or related patterns are repeated, then, at least not in the same number and not the symmetric location patterns; "atavism" plays a role.

Kristine Bonnevie based on embryo data about the development of finger paintings, as well as the familys, twins and population based studies, suggested that papillary patterns depend on the morphology of the toes, in particular, from their symmetry or asymmetry. Individual hereditary but the size of the fingers, the bump pads and some other features are the number of scallops, form, defined by an index, width to length duplicity center patterns (Bonnevie, 1924).

It is known that the study of fingerprints of alleged relatives in evaluations of disputed paternity was the main theme of the second all-Russian Congress of forensic experts (1926). P.S. Semenovskiy (Semenovskiy, 1926), A.A. Sal'kov (Sal'kov, 1926) and $n$ etc. point to the possibility of using the expertise of the disputed paternity of dermatoglyphic method. Discussion on the achievements of Russian and foreign scientists has shown that the use in forensic medicine dermatoglyphic traits must be preceded by their study includes processing a large statistical material and identifying genetic inheritance patterns (Fandeev, 2005).

M.V. Volockoy scrutinized the publication on inheritance patterns, finger pointed out errors in previous works: concluded that genetic factors, that defines the structure of the skin relief, do not have a clutch floor. As proof he cited the results of a comparative analysis of finger patterns of correlation coefficients between fathers and sons, as well as between fathers and daughters (Volockoy, 1939). Later in the study of bed inheritance account fingers he made such findings: bed account better identify inheritance during total than 10 fingers; general grebnevoy and the index of intensity under common genetic control, but overall grebnevoy score poligenen more than the index of intensity; signs are highly genetically deterministic and legacy of their high (Volockoy, 1940).

Thus, the above work of the time period indicated on the complex and sometimes contradictory opinions of the authors the hereditary transmission of papillary pattern. Some scholars denied the possibility of the inheritance of papillary pattern or only in exceptional cases allow the transition patterns are other inherited.-permits the possibility of hereditary transmission of fingerprints and talked only about the similarity, but not their identity.

\section{Disputes Concerning the Hereditary Transfer of Papillary Patterns}

Scientific debate among scholars concerning the hereditary transmission of papillary pattern continued in to the XX century. So, S .Okros examination of 100 cases of undisputed paternity testing found that the skin patterns of each finger the child carry the parts (minucii) homologous finger parents. In this way the mother and father of a child can be accurately established. this method has been used successfully by the author in the 1600 cases of paternity (Okros, 1966).

Palms inheritance patterns, has devoted her work L. Penrose, which the presents estimates of the correlation coefficients for palm patterns have twins developing from different eggs, as well as brothers and sisters. She considers, that environment factors play a greater role in the inheritance of palms patterns compared to the finger (Penrose, 1970).

Later D. Loesch found that hinge on the second mežpal'pevom period, the radial loop gipotenare (pincushion, going from a transverse flexion line under the little finger to the wrist), the axial triradius palm and other patterns are determined by each one pair of genes, and the presence of loops in gomozigotam on recessive genes (Loesch, 1978).

Problem the hereditary transmission of papillary pattern and soviet scientists. For example, V.M. Gindilis and S.A. Finogenova in study genetic fingerprints and palms dermatoglyphic determination on twins and family material used qualitative approaches. Their results showed that the genetic determinism of the palm dermatoglyphic is considerably lower than the finger (the correlation coefficient is 0.35 against 0.80) (Gindilis, Finogenova, 1976).

V.P. Voyitenko and etc. proposed the inheritance model, according to which the rate of generation of deltas determines the phenotype of finger patterns. The authors have identified two different directions of education deltas: spiral, contributing to the formation of two or more deltas, and eventually the emergence of curl, and despiral, that is reducing the number of deltas on the fingers. The first factor, in their view, promotes the formation of whorls, the second forms arc patterns. Both of these factors affect ul'narnuû loop, which, according to their concept, represents the beginning of a pattern. Loops patterns most often observed in Europeans. The spirals factor is ul'narno, and despiralradial (Voyitenko, 1979).

According to I.S. Gusevoy, objective of the research is to use the inheritance patterns of the individual characteristics of the science (Guseva, 1980) and determining the identity of the deceased to his close relatives. She 
believes that in the inheritance of the finger images are three pairs of genes located in the loci $A, L, W$. The seven species phenotype finger patterns that occur in human populations (the only arc on all fingers, only the whorls on all fingers, only loops on all the fingers and various combinations of these patterns) are, in its view, 26 different genotypes.

I.S. Guseva concluded that the number of papillary lines from delta to the center of the pattern either in total or in the local's expression is not a genetically determined trait; inherits only trimming the density. Its proposed model poligennogo picture manual inheritance has not yet received full confirmation when checking (Guseva, 2010).

Proof that papillary patterns are inherited (excluding the full identity, because nature is unique) is the existence of, in particular, the geographical and ethnic identity. Question is, how has this similarity? The answer is no doubt that it has long passed by inheritance from one generation to the next. For example, japanese, chinese, yakut, gypsies, etc. nationality, which comply with the purity of the nation, are against mixed marriages, and thus exclude the genetic influence of one on the other, and as a consequence no dermatoglyphic changes. From generation to generation papillary patterns of the same population, and this has led to the preservation of morphological characteristics of this population.

G.L. Hit' excavated the dermatoglyphic peoples of the USSR and concluded that the whole system of the skin relief is subject to rigorous control gene, which restricts the variation of each trait in the strictly defined limits and, moreover, makes the commensurate level of intra-and inter-group diversity signs. To identify patterns of territorial characteristics of the system are the following interrelated characteristics: delta index, index Cumminsa, axial proximal palmar triradius, uzornost' hypothenar, thenar/1 pad between the toes and the percentage of incremental between the triradiusov. These signs of dermatoglyphic (racial-diagnostic) are involved in the formation of territorial complexes within regions. These complexes are specific to each region, and in most cases demonstrate the interaction of different racial components (Hit', 1983). She studied two groups of old-timers of the Russian population of Krasnoyarsk Krai and Yakutia and determined morphological similarities with the Russians Novgorod region, indicating a common origin. There are the common points and the heterogeneous population of Central Asia: are the alien caucasian group; are mongoloid group.

Tajiks, pamiri people, turkmen, uzbeks and uighurs are the maximum degree of similarities.

Population differentiation is in direct connection with the degree of cross-breeding, which was the leading factor create of the races on the territory of Central Asia, for at least two millennia. The far eastern races have similar combinations of signs, accompanied by increased far eastern traits outside of the USSR from the Japanese, Chinese, Koreans, Vietnamese, Taiwanese tribes (Hit', 1983).

O.M. Unusova and A.P. Boshcenko developed quantitative criteria measures blood close and created algorithms of identification research. They proved that in each family triplete clearly dominate the pattern of one of the characteristics of the same finger parents.

For the first time found that the dominance of one of the parents in the transfer of dermatoglyphic traits is of great personal importance to the toes, and fingers, which previously received attention (Unusova, Boshcenko, 1999).

L.I. Tegako noted that of the birth of the twins third monozngatnyh (developing from one egg), and two thirdsdizigotnye (developing from two or more ova fertilized at the same time). The twins are convenient to study heredity and environmental influences that monozigotnye couples have identical hereditary basis (the genotype). emerging differences between them is a result of the impact of the external environment.

Dizigotnye gemini-animals, from the earliest moments of the developing in the same environment. Diagnosis of zigotnosti twins is based on similarity of different traits in twins pairs (in appearance, color of eyes, hair, blood factors, group gender, etc.). If significant differences in finger and Palm patterns between identical twins more than four brushes, they belong to the dizigotnym, if they are different for the four and less than signs to monozigotnym (Tegako, 2010).

Thus, more and more scientists on the basis of empirical material research have come to a conclusion about the existence of hereditary transmission of papillary pattern, however the mechanism of interaction of genotype and phenotype, that is, identifying genes and alleles that control the drawings on the fingers and toes, as well as the palms, is in need of further research.

\section{The Perspectives of Hereditary Transmission of Papillary Patterns}

Perfect empirical material for study the hereditary transmission of papillary pattern the isolated nation (mononacional'nost') on separate territory in which excluded marriage with other nations. In the modern world, however, the number of such areas is reduced at the expense of last population. In this regard, mention should be made study of the dermatoglyphic O.K Galaktionova an isolated population with well preserved traditional way of economic and cultural life of peoples, in particular, Taymyr, Chukotka, Kamchatka and Yamal. The number of such populations for the past 40 years has decreased due to the socio-economic transformations that took place at various stages in the USSR and 
Russia. Alien population in these territories is small and has other signs of dermatoglyphic due to lack of genetic relationships with the indigenous population, and therefore differs from it.

Heredity - this obshebiologicheskoe phenomenon, steward ships in the presence of similar traits in parents and offspring due to transmission through sexual cages (this transfer and inheritance) specific material structures (chromosomes with the DNK, cytoplasmik elements). Heredity can be traced to two related kin individuals (motherdaughter, grandfather-grandson).The refore, the longer will be the population came in contact with the indigenous population, the more opportunities through kinship to changes of dermatoglyphics traits.

The author in analysis had included the following signs for dermatoglyphics not part of the population:

a) quality - the percentage of occurrence of finger patterns on the fingers (W, UL, RL, A), mejpaltsevykh balls of palm (Th/I, II, III, IV, Hy) and feet (Thd II, Thp, II, III, IV, Hd, Hp, Hd/Hp, Cal). Of the main palms line or cut line or noted the lack of $\mathrm{C}(\mathrm{O}, \mathrm{X}, \mathrm{x})$. The feet had to be signs of the first finger only, since the other fingers do not leave the picture;

б) quantitative-grebnevyj account (RC) on fingers (I-V) and stop (I), the grebnevyj account (TRC -the number of scallops on 10 fingers), the index of intensity (PII -the number of triradiusov on 10 fingers), the main index of the palmar (Mli - total end of main palmars lines A and D), palmar angle atd grebnevyj palmars balls of your account $a-b, b-c, c-d$.

The author will closer to address important issues related to the transmission of hereditary papillary patterns. With the assistance of quantitative indicators is an opportunity to get the most comprehensive evaluation based on the behavior of genetic systems (Galaktionov, 2008).

A.G. Sidorenko study of the palmar dermatoglyphic traits(quantitative and qualitative indicators, taking into account the topography of triradiusov and volyarnogo image, lack of primary and secondary triradiusov) and inheritance patterns and signs of bed account. Characteristic bed account of Palms was carried out by two groups of signs, that is on the main (regular) and triradiusov (rare) triradiusov.

The detail of bed accounts for groups with small, medium and large number of papillary lines revealed significant correlations that indicate hereditary predisposition to this system of dermatoglyphic traits of palms. Papillary patterns of the hands and feet have a hereditary basis, dependent on race, gender, the functional asymmetry of the limbs and some congenital diseases, have age stability and does not change significantly over a life time.

The correlation of rare dermatoglyphic features between the palms and the true parents. Further improvement of the accuracy of counting bed account of palms will identify the individual disputed paternity, maternity or substitution of children (Sidorenko, 2006).

L.U. Spak analysis of inheritance form patterns on middle and proximal phalanges in russians and nganasans, which showed that the most likely poligennyj the nature of inheritance patterns, with penetrance differently expressed on individual patterns, and for each of the base systems. The unequal distribution of arch patterns and waves in men and women showed that the inheritance of these traits may be limited or controlled by gender.

Developed quantitative criteria for assessing the probability of kinship for each system base of patterns and combinations. Differentiating capabilities of each base is different, especially on systems bilateral'nom level. Expert assessment of the probability of kinship shall be carried out taking into account the bilateral diagnosis, which determines the total dominance of the mother on the patterns on his left hand, the right hand of the father-dominance. On both hands, percentage of reliable solutions in establishing paternity on the basis of three base systems is: $44 \%$ - when comparing a child with his father, $66 \%$ - with her mother. Simultaneous use of patterns for all three systems increases the efficiency of the increases the effectiveness of diagnosis and comparison with both parents can reliably determine the identity of "his" 95\% of cases in children (Spak, 2003).

A.L. Fandeev researched besides phalanges of fingers and foot. Results showed, that between the dermatoglyphic signs of the distal phalanges hands and foot there is general morphological similarities, however, the corresponding indications on the fingers of the upper and lower extremities are distributed differently. The formation of the type, height, pattern, form, flow lines in the center of the pattern, as well as the number of deltas on the distal phalanges hands and feet of the child depends on the combination of dermatoglyphic traits for homologous fingers parents.

Not all dermatoglyphic are inherited traits from the father and the mother in the same way, so the study of families, a distinction must be made between the parents according to their gender. Comparison of parents with true and false child on 80 dermatoglyphics grounds of the distal phalanges revealed that only $4 \%$ of the cases, the child is similar to both parents equally, just as likely, he may be similar and the outsiders of peoples. The dominant parent child look like an average of $68.4-69.0 \%$, to the other parent at $58,4-59,1 \%$, a coincidence not signs between relatives in an average of $61.7-63.6 \%$.

Authentic proof of kinship on dermatoglyphic characteristics of fingers is possible in $4.78 \%$, excluding the $5.93 \%$, probable proof of relationship-a $33.91 \%$, probable rejection - in $24,58 \%$, indeterminate result - in $30.80 \%$. Reliable confirmation of the relationship on the grounds of toes foot - in $2.19 \%$, exception - in $2.36 \%$, the likely confirmation of 
relationship - in $27.60 \%$, likely its negation - in $17.50 \%$, unspecified result - in $50.40 \%$. On the grounds of the fingers of the upper and lower extremities reliable proof of kinship may - in 15.89\%, in its exception - in $13.71 \%$, probable confirmation of relationship - in $22.48 \%$, probable negation - in $24.60 \%$, result is indeterminate - in $23.32 \%$.

Accuracy of the allocation of cases to the total confirmation of the relationship on the grounds of the fingers of the upper and lower extremities is $86 \%$, its negation in $82.7 \%$, in total- $84.3 \%$. Almost true to $-29.6 \%$, probable- $47.1 \%$. The use of the equations obtained by the method of Fisher, a reliable confirmation or denial of the relationship (Fandeev, 2005).

O.M. Fandeeva with the help of new information models with different combinations of fingers of the upper and lower extremities has created a universal diagnostic algorithms determine the consanguinity. The versatility of the algorithm is that, first, an unknown relative can be any member of the family unit, the intended second, blood relationship can be specified both with and without regard to the gender of the child.

It has multiple options for inheritance of dermatoglyphic traits: a) mainly from the father, b) of mother, c) from both parents, and also generated regardless of the genotypes of the parents (a complex interaction of factors of external and internal environment). The degree of determination, the signs are different, therefore, when determining consanguinity, in addition to comparative analysis of occurrence characteristics in the population and in particular family group, you must at the same time take into account the features of all three members of an alleged family group. The data obtained allow to develop nine original diagnostic models to confirm or refute the bloodline dermatoglyphic method (Fandeeva, 2010).

N.V. Rudakov for the first time in a study of children of mixed marriages of russian and siberian tatars south of the Tyumen region have used complex dermatoglyphic traits: pattern type, height, number of deltas, the shape of the flow lines in the center of the pattern. He developed an original classification form flow lines in the center of the pattern on the distal phalanges, hands and foot, that made it possible to identify the patterns of inheritance of this trait.

Siberian tatars south of West Siberia, as the largest indigenous group, have a number of characteristics - primary primary palmar main lines end the source text A in the proximal position - box 1 (up to $22 \%$ ), 3 (up to $69 \%$ ), end of the line $D$ in the field of 9 with up to $43 \%$, index of Kamminsa up to 7,51 , frequency of axial triradiusa of the proximal to $78.80 \%$, frequency ul'narnyh hinges to $45 \%$, whorl patterns to $46 \%$, a value del'tovogo index to 7.00 and the size of the total bed account men 148, in women -137.

Dermatoglyphics of last Russian population has reliable dermatoglyphic differences from the native population in the more distal end of palmar main lines A - in the field 3 (up to $51 \%$ ), in the field $4(21 \%$ ), in the field 5 (up to $17 \%$ ), end of the line D in field $9(39 \%)$ and in field 11 (up to $46 \%$ ) at 8.23 to Kamminsa index value. Frequency ul'narnyh of loops in russian men reaches $58 \%$, in women up to - $60 \%$, value-del'tovogo index up to -6.00 , size bed general account in men 131.32 and in women -124.53 .

The children of mixed marriages, the tatars and the russians have a number of characteristics of the structure of skin patterns. The value of the indicators dermatoglyphic directed towards in side of the specific to the indigenous population, completion of primary palmar lines $\mathrm{A}$ in the field 1 with frequency $5,00 \%$, in the field 3 with frequency $55,80 \%$, in the field 4 with frequency $19,17 \%$, lines end $D$ in the field 9 with frequency $47,64 \%$, in the field 11 with frequency $40,54 \%$ to Kamminsa index value 7,80 and frequency of axial triradiusa of the proximal $75,33 \%$. Loop patterns for men $36,67 \%$, for women $-57,56 \%$, whorl patterns for men $-61,01 \%$, for women $-54,44 \%$. Delta index has a value for men7,91, for women - 7,99. Total combed through for men -168,60, for women -167,11 (Rudakov, 2015).

Found dermatoglyphic especially children born in mixed marriages, testifying to the processes of genetic adaptation of this population to local natural conditions, the prevalence of children of mixed marriages of the indigenous population.

Authentic proof of kinship on dermatoglyphic characteristics of fingers is possible - in 4,78\%, exception - in $5,93 \%$, the likely proof of relationship - in 33,91\%, the likely negation- in $24,58 \%$, unspecified the result- in $30,80 \%$. Reliable confirmation of the relationship on the grounds of foot in 2,19\%, exception - in 2,36\%, the likely proof of relationship - in 27,6 the likely negation- in $17,5 \%$, unspecified the result- in $50,4 \%$.

On the grounds of the fingers of the upper and lower extremities reliable confirmation of relationship possible in $15,89 \%$, exception - in $13,71 \%$, the likely proof of relationship - in $22,48 \%$, the likely negation- in $24,60 \%$, unspecified the result- in $23,32 \%$.

Thus, the data indicate that recent studies of inheritance patterns are more manual. Held interesting scientific studies that focus on a variety of qualitative and quantitative dermatoglyphic featured a distal falangam of fingers, palms and foot. 


\section{Conclusion}

In the long term, of course, all the proposals considered scholars deserve further study. It shows that, on the basis of a comparative study of dermatoglyphic traits may be as reliable and credible proof of kinship. In the case of an uncertain result, we recommend that you extend the number of dermatoglyphic traits studied, for example, the pal'cevomu grebnevomu account, grebnevomu account between triradiusami the palms and boots, total number of deltas in one or more limbs, indices of pattern types (Furugata, Dankmeyera, Pollya). Study the patterns triradiusy of palms and soles, and plantar palms end of lines, etc. If a fair solution of the above signs were not enough, you must use the individualizing symptoms such as: the outline of the pattern, the location of its center (vertically and horizontally), type and disposition of triradiusov, the position of the lines, the lines flow angles interposition in the patterns.

There are some types of informative enough transmitted by inheritance of dysplasia, some types of patterns, forming white lines, some kinds of minucius and other (Rudakov, 2015). Dermatoglyphic methods to obtain information about the hereditary transmission of papillary pattern to explore papillary pattern type, its type, a form of dysplasia (Yarovenko, 2014). So, arc pattern happens to be of the following types: simple; the tent; ARC pattern with undefined structure of the centre; false-loop; false-whorl. For the arc pattern further signs is his height, which is measured using a special Protractor made of transparent plastic plate, which are corresponding angles (Zvyagin, Rakitin, 2012). For the scientific and the practical application of the dermatoglyphickogo method to publish the results of testing are important in practice to the analysis of statistical analysis on theoretical issues in forensic medicine and forensic science to the study of personality (Yarovenko, 2011, Yarovenko, 2013).

\section{References}

Elderton, E.M. 1920. On the inheritance of the finger print. Biometrica. № 12, pp. 57- 91.

Fandeev, A.L. 2005. Examination of relationship on the grounds of a brush and stops system. Moscow, pp. 3-17.

Fandeeva, O.M. 2010. Structural organization of papillary pattern fingers and their features in family groups. St. Petersburg, pp. 3-31.

Galaktionov, O.K. 2008. Dermatoglyphic in population-based studies (analysis of quantitative and qualitative indicators in archaic mongoloid ethnic groups). Vladivostok, pp. 25-26,

Galton, F. 1892. Finger prints. London: Macmillan and Co.,

Gejndl', R. 1927. Scientific palmistry fingerprinting and other methods of criminal technique in the investigation of crimes" Moscow, pp. 7-22.

Gindilis, V.M., Finogenova S.A. 1976. Heredity characteristics of digital and palmar dermatoglyphic human Genetics. vol. XII, № 8, pp 139-150.

Guseva, I.S. 2010. Digital human patterns. Morphology. Morphogenesis. Genetics. Dermatoglyphic as a marker in the medical and sports anthropology. Minsk.

Guseva, I.S. 1980. The choice of signs for dermatoglyphic analysis. Health care of Belarus. № 9. pp. 32-34.

Hit', G.L. 1983. Dermatoglyphics of peoples of the USSR. Moscow, p. 15 and 18.

Komissarov, V.I., Levin, E.S. 1997. Fingerprinting in Russia: problems and ways of their solution. //Law. № 1. pp. 127-131.

Kristine Bonnevie. 1924. Studies on papillary patterns of human fingers. Journal of Genetics November, Volume 15 , Issue 1.

Loesch, D. 1978. Topological classification and genetical studies of dermatoglyphic patterns. Journal of human evolution. pp. 669-677.

Okros, S. 1966. The Heredity of papillary patterns. Budapest.

Penrose, L. 1970. The effect of sex chromosomes on some characteristics of dermal ridges on palms and fingerprints. Genet. Pol. vol. 10, № 3-4. pp. 328-331.

Rudakov, N.V. 2015. Dermatoglyphics children of mixed marriages aboriginal and of last population South of the Tyumen region. Tyumen, p. 17.

Sal'kov, A.A. 1926. Fingerprint when establishing the value of the sibling similarities. Proc. II All-Russian Congress of forensic experts.. Ulyanovsk. pp. 103-106.

Semenovskiy, P.S. 1926. The issue of hereditary tactile patterns. Proc. II All-Russian Congress of forensic experts.. Ulyanovsk. pp. 99102

Sidorenko, A.G. 2006. Palmar dermatoglyphic features in forensic identification. Moscow, pp. 3-5.

Spak, L.U. 2003. Dermatoglyphics phalanges of fingers. Moscow, pp. 3-15.

Tegako, L.I. 2010. Scientific palmistry.. Moscow, p. 118,

Unusova, O.M., Boshcenko A.P. 1999. Independent domination of parents on dermatoglyphicomu set of finger and foot. 53 materials of the Scientific Conference of young scientists. Rostov-na-Donu.

Volockoy, M.V. 1939. The genetics of papillary pattern toes (234 study pairs of identical twins) (1936). In: proceedings of the medicalgenetic Institute. Moscow, pp. 404-431.

Volockoy, M.V. 1940. Genetics of skin relief. The number of lines in the central designs. Scientists note MGU. Anthropology. Moscow, vol. 34, pp. 209-245.

Voyitenko, V.P. and etc. 1979. The inheritance pattern of human/manual. Genetics. vol. 15, № 7, pp. 1317-1326. 
Yarovenko, V.V. 2014. Form papillary pattern-like object of dermatoglyphic studies. Problems of the use of forensic expertise in law enforcement: the materials of the all-Russian scientific conference. Tomsk, pp. 115-118.

Yarovenko, V.V. 2013. Dermatoglyphicheskie personality characteristics in the context of the determination of crime. Baikal Criminology journal. Irkutsk, № 1. pp. 36-40.

Yarovenko, V.V. 2011. Kriminalisticheskaya dermatoglyphica. Vladivostok.

Zvyagin, V.N., Rakitin, V.N. 2012. Dermatoglyphics: encyclopedic dictionary. Perm, pp. 83-84. 